\title{
Determinación de los grupos sanguíneos
}

\author{
POR ENRIQUE CIOTOLA \\ Ayudante de Parasitologia en la Facultad de Medicina
}

En junio del áño pasado, efectué, por primera vez entre nosotros, la determinación de los grupos sanguíneos y reservé los sueros pertenecientes a los grupos II y III que he uti. lizado ulteriormente.

Antes que Egrdi publicara su monocratía, esta determinacion era compleja, pues recuería repetir las investigaciones en las grandes proporciones como lo habia hecho Moss, si es que no se deseaba estar sometido a la dependencia de los laboratorios que estuvieran dotados de los sueros II y III.

Estudiando detenidamente el cuadro de Moss, fué que Egidi, llegó a formular las conclusiones que han simplificado grandemente la técnica a seguir; ellas han sido, las que han orientado estas investigaciones, y las consideraciones que expongo.

Los seres humanos pueden ser reunidos en cuatro grupos, segun las características de las reciprocas reacciones: aglutinante y hemolitica, de los sueros con relación a los hematíes.

Para Moss, las personas que pertenecen al grupo I, poseen sangre cuyo suero no aglutina ni hemoliza los hematies 


\section{Cuadro de Moss}

Sweros $\left\{\begin{array}{ccccc} & \text { I } & \text { II } & \text { III } & \text { IV } \\ \text { I } & 0 & - & - & - \\ \text { II } & + & 0 & + & - \\ \text { III } & + & + & 0 & - \\ \text { IV } & + & + & + & 0\end{array}\right.$

de los otros grupos; y hematies, que son aglutinados y hemolizados por los sucros de los grupos II, III y IV.

Las personas que pertenecen al grupo IV, poseen sangre cuyo suero tiene acción aglutinante y hemolítica bacia los hematies de los otros grupos; y hematies que no son aglutinados por los sueros de los grupos I, II y III.

Las personas que pertenecen al grupo II, tienen saugre cuyo suero aglutina y hemoliza los hematies de los grupos I y III; y hematies que son aglutinádos y hemolizados por los sueros de los girupos III y IV.

Las personas que pertenecen al grupo III, poseen sangre cuyo suero aglutiná y hemolizá los hematies de los gru. pos I y II; y bematies que son aglutinados y hemolizados por los grupos II y IV.

Desde que Esmr, dis a conocer su tésuici, la determinawación de estos grupos, no requiele, en la inmensa mayolía de los cásos, si no obtener de 20 personas. lna pertan de sángre que se mezcla, cada ana, en un cc. aproximadamente de una solución de citrato de sodio al $2 \%$.

Provistos de 20 suspensiones de glóbulos rojos que denominaremos con las letras minúsculas del alfabeto, y de suero (A), proveniente de la persona que ha cedido los hematies (a); ponemosen presencia, una gota de este suero con uná gota de uná suspensión globular, y observamos su acción aglutinánte.

Repitiendo la investiración con los demás hematies, ob. servamos la característica de la acción aglutinante del suero con reláción a los hemáties.

Mientras Egidr, contempló una posibilidad; la más corriente de hallar en la práctica; nosotros trataremos de los diferentes casos que se presentan, segun la clase de aglutininá de que esté provisto el suero; o que carezca de ella. 
Tres posibilidades pueden ofrecerse:

$1^{a}$ Posibilidad $\quad 3^{a}$ Posibilidad

Suero (A)

Suero $(N) \quad$ Suero $(M)$ Suero $(H)$

$1^{a}$ P. $2^{a}$ P. $3^{a}$ P. $\quad 3^{a}$ P. $3^{a}$ P. $\quad 3^{a}$ P. $\quad 3^{a}$ P. $\quad 3^{a}$ P.

$1^{\text {a V. }} 2^{\text {a V V. }} 1^{\text {a }} \mathrm{V} .2^{\text {a }} \mathrm{V}$. Tipo I

Gls.

\begin{tabular}{|c|c|c|c|c|c|c|c|}
\hline a... 0 & 0 & 0 & - & + & - & + & - \\
\hline b.... + & - & + & + & - & - & + & + \\
\hline$c \ldots+$ & - & + & + & - & + & - & + \\
\hline $\mathrm{d} \ldots+$ & - & - & - & - & - & - & 一 \\
\hline e...t & - & - & + & - & - & + & - \\
\hline f... & - & - & - & - & - & + & - \\
\hline g.... & - & - & + & + & - & - & - \\
\hline b.... & - & + & + & + & + & - & 0 \\
\hline $\mathrm{i} \ldots .+$ & - & + & - & - & - & - & + \\
\hline$j \ldots+$ & - & + & - & - & - & + & + \\
\hline$k \ldots+$ & - & - & - & + & - & + & 一 \\
\hline $1 \ldots+$ & - & + & + & - & + & + & + \\
\hline $\mathrm{m} . . .+$ & - & + & + & + & 0 & 0 & + \\
\hline$n \ldots+$ & - & - & 0 & 0 & - & - & 一 \\
\hline $0 \ldots+$ & - & + & + & + & - & - & + \\
\hline$p \ldots+$ & - & + & + & + & + & + & + \\
\hline$q \ldots+$ & 一 & + & - & - & - & + & + \\
\hline$r \ldots+$ & - & + & + & - & - & - & + \\
\hline s.... + & - & - & - & - & - & - & - \\
\hline t.... & - & + & + & + & + & - & \\
\hline
\end{tabular}

$1^{\text {a }}$ Posibilidad.-El suero a identificar, ha aglutinado todas las suspensiones globulares. En este caso deducimos que el suero puede pertenecer: $1^{\circ}$ al IV grupo, y las demás personas a los grupos I, II y III, o a uno solo de estos; $2^{\circ}$ al II o III grupo, correspondiendo los glóbulos a los grupos I y III o a uno solo de estos, en el 1er. caso; o al I y II, o uno de ellos en el segundo caso.

El que correspondan todus los glóbulos a un sologrupo, es una posibilidad muy rara, por no decirque es imposible que se presente en lá práctica.

Para sáber a qué grupo de estos corresponde, sácamos $10 \mathrm{cc}$. de sangre a otra de las 20 personas, e investigamos la acción aglutiuante de su suero.

Este suero a su vez puede ofrecer dos variedades: $1^{\text {R }}$ variedad: el suero presenta lás cáracterísticas de aglutinabili- 
darl correspondientes a la 2 posibilidad; lo rechazamos, se trata de un suero del grupo I; extraemos sangre a otra persona, hasta hallar un suero que ofrezca los caracteres de la $3^{*}$ posibilidad; $2^{a}$ varierlad: el suero ofrece los carncteres de aglutinabilidad correspondientes a la $3^{\circ}$ posibilidar.

Si en la $1^{\text {a }}$ variedad, al extraer sangre a las judemás per. sonas; sus sueros ofrecieran los caracteres de aglutinabilidad dela $2^{a}$ posibilidad, se tratará de sueros correspondientes al mismo grupo I; y el primer suero perteneceria al grupo IV. En estas condiciones, habría que escoger otras 20 personas, y crmenzar de nuevo la investigación.

En poseción de un suero que ofrezca los caracteres de aglutinabilidad de la $3^{*}$ posibilidad, podemus estar presentes a dos variedades de esta posibilidad.

$1^{\text {a }}$ varielad: este suero no ha aglutinado los hematies correspondientes a la persona de la que hemos obtenido el primer suero. Esto nos indica, que pertenece, el primer suero, al IV grupo; y el al timo suero, a los grupos II o III, igual grupo al que pertenecen las personas cuyos hematies, no han sido aglutinados únicamente por este suero.

Al tratar de la $3^{a}$ posibilidad, indicaremos las investigaciones que deben practicirse para completar la determinación.

$2^{2}$ variedad: este suero. ha aglutinado los hematies correspondientes a la persona de lá que bemos obtenido el primer suero. Deducimos, que estos sueros corresponden a los grupos II y Ill que son los que deseábamos obtener.

$2^{9}$ Posibilidad-El suero a identificar, no ha aglutinado ninguna suspensión globular. En este caso deducimos que puede pertenecer: $i^{\circ}$ al grupo $I$, correspondiendo los hematíes a los grupos II. III y IV. o sólo a uno de estos; $2^{\circ}$ al grupo II, III y IV y los hematies corresponder al mismo grupo.

Para saber a cual de estos grupos corresponde el suero, sacamos sangre a otras de las personas que haya cedido hematíes; su suero, puede ofiecer dos variedades:

$1^{\text {a }}$ Variedad; el suero ofiece los caracteres de aglutinabilidad de la $1^{a}$ o $3^{a}$ posibilidad.

Si el suero ofrece los caracteres de aglutinabilidad de la $1^{*}$ posibilidad, nos indica que corresponde al IV grupo. y el primer suero al grupo I; según lo expuesto anteriormente. Hay que sacar sangre a otras personas, hasta que hallemos 
un suero que ofrezca los caracteres de aglutinabilidad correspondiente a la $3^{a}$ posibilidad.

Si el suero ofrece los caracteres de aglutinabilidad de la $3^{*}$ posibilidad, $y$ aglutinado los hematies correspondiente a la persona de la que obtuvimos el primer suero; deducimos que estéltimo, pertenece al grupo I y que el fltinı suero, corresponde al grupo II o III.

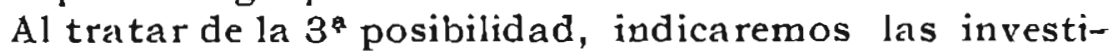
gaciones á seguir.

Podrian en esta variedad, ofiecer los demás sueros, los caracteres de aglutinabilidad de la $1^{\text {* }}$ posibilidad; entonces se trataría de sueros que corresponderían al mismo grupo.

En ese caso, habria que escoger otras 20 personas y comenzar de nuevo las investigaciones.

$2^{\text {a }}$ Variedad; el suero obtenido, ofrece los caracteres de aglutinabilidad correspondiente a la $2^{a}$ posibilıdad, igual caracter que presentó el primer suero. Se trata de personas que pertenecen al mismo grupo.

En este caso, hay que escoger otras 20 personas y comenzar de nuevo las investigaciones.

$3^{3}$ Posibrlidad. -El suero a identificar, ha aglutinado algunas suspensiones globulares y otras no. Este suero puede pertenecer al grupo II, III o IV.

Si se trata de un suero del grupo IV, los hematíes no aglutinados, corresponden al mismo grupo; y los aglutinados, al I, II y III o a uno solo de ellos.

Si se trata de un suero del grupo II, los hematies aglutinados corresponden a los grupos I y II o a uno de ellos; y los no aglutinados, al III y IV o a uno de ellos.

Si se trata de un suero del grupo III, los bematíes aglutinados, corresponden a los grupos I y II o a uno de ellos; y los no aglutinados, al III y IV o á uno de ellos.

Segan esto, si sacamos sangre a una persona cuyos glóbulos hayan sido aglutinados, su suero puede presentar dos variedades: $1^{\text {a }}$ variedad: of rece la posibilidad $2^{\text {a }}$; lo que nos indica que pertenece al primer grupo, desechamos este suero y sácamos sangre a otra persona cuyos glóbulos hályan sido aglutinados, hasta hallar un suero que ofrezca la posibilidard $3^{\text {a. }}$.

Podía ser que no hallaramos ninguna persona que ofreciera esta posibilidad, lo que indicaría que todas las personas cuyos heratíes han sido aglutinados, pertenecen al grupo I. 
En esta condición, muy rara, hay que escoger otras $20^{\circ}$ personas y comenzar de nuevo las investigaciones.

Podría sacarse sangre, a las personas cuyos gl6bulos no hubieran sido aglutinados por el primer suero.

Si los sueros pertenecientes a estas personas, presentan todos, la característica de aglutinabilidad de la $1^{\text {* }}$ posibilidad, los rechazamos por corresponder al grupo IV. Lo queelimina también esta posibilidad de determinación.

Si no se presenta esta everitualidad, al sacar sangre a una de las personas cuyos glóbulos no hubieran sido aglutinados, su suero puede ofrecer los caracteres de aglutinabilidad, correspondiente a la $3^{a}$ posibilidad, bajo una de las variedades que describiremos.

$2^{\mathrm{a}}$ variedad; el suero obtenido ofrece los caracteres de aglutinabilidad de la $3^{a}$ posibilidad.

Este supro a su vez, puede ofrecer dos variedades de aglutinabilidad, de esta posibilidad.

L variedad: El suero obtenido, aglutina algunas suspensiones globulares y otras 110 ; no habiendo aglutinado los hematies correspondientes al primer suero, ni los que no lo fueron por éste.

En este caso, el primer suero pertenece al grupo IV y el Gitimo all II o III. En estas condiciones desechamos el primer suero, y extraemos sangre a una de las personas cuyos globulos hayan sido aglutinados por el último suero. Estas personas no pueden pertenecer sino a los grupos I y II o III o uno de estos únicamente.

Si el suero de la sangre extráída, ofrece los caracteres de aglutinabilidad correspondicutes a la 2 a. posibilidad; lo que wos indica que corresponde al grupo I; debemossacar sangre a otra persona, hasta hallar un suero que ofrezca los caracteres de la 3a. posibilidasl: tipu I.

Estos dos sueros hallarlos, pertenecen entonces a los grupos II o III, pero diferentes entre ellos, que eran los que deseabamos obtener.

Si todos los sueros, offecieran los caracteres de aglutinábiliclad, correspondientes a la 2a. posibilidad, deduciriamos que pertenecerian al grupo I, entonces deberiamos escoger otras 20 personas y comenzar de nuevo las investigaciones.

$2^{\text {a }}$ variedad; el suero obtenido, aglutina algunas suspensiones globulares y otras no; aglutinando los hematíes. correspondientes al primer suero. 
Deducimos que estos sueros corresponden a los grupos II o III, y son diferentes entre ellos; siendo los que deseaba. mos hallar.

Por estos métodos de eliminación, estamos en posesión de dos sueros, que sabemos que pertenecen: el uno, al grupo II $y$ el otro al grupo III, pero. no podríamos referirlos como lo hace Egidi, a cleterminario grupo del cuadro de Moss, pues seríc cverutual si acertaramos, y podrínmos haber fijado un suero II como perteneciente al grupo III y vice versa.

P'ero, si observamos que Yanskx.

CUADRO DE YANSKY

\section{Glóbulos}

Sueros $\left\{\begin{array}{ccccc} & \text { I } & \text { II } & \text { III } & \text { IV } \\ \text { I } & 0 & + & + & + \\ \text { II } & - & 0 & + & + \\ \text { III } & - & + & 0 & + \\ \text { IV } & - & - & - & 0\end{array}\right.$

ha seguido en su clasificación de los grapos sanguineos un orden inverso que el de Moss, podemos usar una denominación binoninal. Según ella, uno de estos sueros pertenecería al grupo II Moss-Yansky; y el otro al grupo III Moss YANSKY.

Sin equivocarnos, denominariámos dos grupos sanguineos al que corresponderían las personas cuya sangre, ofrecería suero y hematies, provistos de propiedades aglutinantes y aglutinables, idénticas con relación a los grupos I y IV pero contraria entre ellas.

Ya en posesión de los sueros II y III Moss Xansky, para la determinación de los grupos sánguineos, sacámos una gota de sangre, y la mezclamos en un cc, aproximadamente - de una solución de citráto de sodio al $2 \%$, y ponemos uná gota de esta suspensión, en presenciá de una gota de suero.

Las personas cuyos glóbulos rojos son aglutinados por los dos sueros pertenecen al grupo I; pertenecen al grupo IV aquellas cuyas hematíes no han sido aglutinados por los dos sueros; y pertenecen a los grupos II o III, aquellas cuyos hematíes han sido aglutinados fnicamente por los sueros III O II. 
Sueros

$$
\text { II } \mathrm{M}-\mathrm{Y} \quad \text { III } \mathrm{M}-\mathrm{Y}
$$

Glóbulos $\left\{\begin{array}{lll}\text { I } & + & + \\ \text { II } & - & + \\ \text { III } & + & - \\ \text { IV } & -- & -\end{array}\right.$

El signo $(+)$ indica que los glóbulos han sido aglutinados. Estáaglutinación puede observarse macroscópicamente por la formáñ de grumos en vez de la homogeneidad de la suspensión que se observa cuandola reacción aglu. tinante ha sido negativa.

La aglutinabilidad de los hematies puede observarse mejor al microscopio, Los glóbulos aglutinados están unidos por sus bordes y no por sus caras en forma de pilas de moneda.

Las aglutinas de los sueros II y III se conservan durante muchos meses impidiendo el desarrollo microbiano con la adición de fluoruro de sodio. 